\title{
FORMAÇÃO E ATUAÇÃO PROFISSIONAL: EGRESSOS DO CURSO DE LAZER E TURISMO - USP
}

\author{
iD Carla Augusta Nogueira Lima e Santos \\ Doutora \\ Departamento de Ciências do Movimento Humano da \\ Universidade do Estado de Minas Gerais (UEMG). \\ Belo Horizonte / MG. Brasil. \\ carla.santos@uemg.br \\ Hélder Ferreira Isayama \\ Doutor \\ Escola de Educação Física, Fisioterapia e Terapia Educacional da \\ Universidade Federal de Minas Gerais (UFMG). \\ Belo Horizonte / MG. Brasil. \\ helderisayama@yahoo.com.br
}

Objetivo: Identificar a inserção dos egressos do curso Lazer e Turismo, da Escola de Artes, Ciências e Humanidades da USP, no mercado de trabalho, reconhecendo os setores de atuação aos quais estão vinculados e as funções que desenvolvem.

Metodologia: A estratégia escolhida para a coleta de dados combinou as pesquisas bibliográfica, documental (projeto pedagógico do curso e site da instituição) e de campo. A pesquisa de campo foi realizada com 73 egressos, mediante aplicação de questionário online.

Originalidade/relevância: Ter conhecimento da inserção dos egressos no mercado de trabalho, bem como dos setores em que atuam e das funções que desenvolvem é uma forma de compreender a identidade dos profissionais do lazer.

Principais resultados: Foi possível identificar que: 52,1\% dos ex alunos não estão atuando na área em que se formaram. Aqueles que estão atuando no campo do lazer $(47,9 \%)$ trabalham no setor privado $(81,6 \%)$ e possuem vínculo trabalhista no regime da CLT $(54,1 \%)$. Os egressos pesquisados atuam em diferentes locais e assumem funções de elaboração, execução e coordenação de vivências de lazer e turismo, além do trabalho com consultoria e gestão de empresas.

Contribuições teóricas metodológicas: Consideramos que as pesquisas com egressos são uma forma de retratar a dinâmica do mercado de trabalho, bem como avaliar os processos formativos ofertados.

Palavras-chave: Lazer Turismo. Formação e Atuação profissional. Egressos. Mercado de Trabalho.

\section{Cite como}

American Psychological Association (APA)

Lima e Santos, C. A. N., \& Isayama. H. F. (set./dez. 2020). Formação e atuação profissional: egressos do curso de Lazer e Turismo - USP. PODIUM Sport, Leisure and Tourism Review, São Paulo, 9(3), 337-369. https://doi.org/10.5585/podium.v9i3.14684. 


\section{TRAINING AND PROFESSIONAL PERFORMANCE: LEAVES FROM THE LEISURE AND TOURISM COURSE - USP}

Objective: To identify the insertion in the job market of graduates of the "Leisure and Tourism" program, from the School of Arts, Sciences and Humanities at USP, recognizing the sectors of activity to which they are linked and the functions they perform.

Methodology: The strategy chosen for data collection included bibliographic and documental research (study of the pedagogical project of the course and the institution's website) and field research. The field research was carried out with 73 graduates through an online questionnaire.

Originality / relevance: To have knowledge of the insertion of the graduates in the job market, as well as of the sectors in which they operate and the functions they perfomr is a way of understanding the identity of leisure professionals.

Main results: It was possible to identify that: $52.1 \%$ of former students are not working in the area in which they graduated. Those who are working in the leisure field $(47.9 \%)$ work in the private sector $(81.6 \%)$ and are employed under the CLT regime $(54.1 \%)$. The surveyed graduates work in different locations and have the functions of elaborating, executing and coordinating leisure and tourism experiences, in addition to working as consultancy and business management.

Theoretical methodological contributions: We consider that research with graduates is a way of portraying the dynamics of the labor market, as well as it is a way of evaluating the training processes offered.

Keywords: Leisure. Tourism. Training and professional performance. Graduates. Labor market.

\section{FORMACIÓN Y ACCIÓN PROFESIONAL: SALIDAS DEL CURSO DE OCIO Y TURISMO - USP}

Objetivo: Identificar la inserción de los egresados del curso Ocio y Turismo, de la Facultad de Artes, Ciencias y Humanidades de la USP en el mercado laboral, reconociendo los sectores de actividad a los que están vinculados y las funciones que desarrollan.

Metodología: La estrategia elegida para la recolección de datos combinó investigación bibliográfica, documental (proyecto pedagógico del curso y sitio web de la institución) e investigación de campo. La investigación de campo se realizó con 73 graduados a través de un cuestionario en línea.

Originalidad/relevancia: Conocer la inserción de los egresados en el mercado laboral, así como de los sectores en los que trabajan y las funciones que desarrollan es una forma de entender la identidad de los profesionales del ocio.

Principales resultados: Se pudo identificar que: $52,1 \%$ de los exalumnos no se encuentran trabajando en el área en la que se graduaron. Quienes trabajan en el ámbito del ocio $(47,9 \%)$ trabajan en el sector privado $(81,6 \%)$ y están empleados en el régimen CLT $(54,1 \%)$. Los egresados encuestados trabajan en distintas localizaciones y asumen las funciones de elaboración, ejecución y coordinación de experiencias de ocio y turismo, además de desempeñarse como consultores y dirección de empresas. 
Aportes teóricos metodológicos: Consideramos que la investigación con egresados es una forma de retratar la dinámica del mercado laboral, así como, es una forma de evaluar los procesos formativos ofrecidos.

Palabras clave: Ocio. Turismo. Formación y desempeño profesional. Graduados. Mercado de trabajo.

\section{Introdução}

Os debates sobre a formação e a atuação de profissionais para e no mercado de trabalho em lazer têm recebido incentivos e, por isso, motivado o surgimento de reflexões críticas, com vistas à construção de um modelo de sociedade mais humano, solidário e democrático. No campo do lazer, diversos autores nacionais (Arruda, 2018; Santos \& Isayama, 2014; Silva \& Isayama, 2017) e internacionais (Henderson, 2011; Haworth, 2006; Lyons \& brown, 2003; Msengi, Faland, Pedescleaux, Mcgloster, \& yang, 2007) têm procurado estudar essa temática a partir do olhar multidisciplinar, com vistas à concretização de propostas interdisciplinares, caracterizadas pela contribuição de diferentes áreas.

Analisando o contexto do lazer, destacamos o crescimento das oportunidades de formação no campo e, consequentemente, a emergência de diferentes currículos de formação. No Brasil, autores como Isayama (2015), Marcellino (2010) e Gomes e Melo (2003) afirmam que as oportunidades de formação profissional estão vinculadas a um "promissor" mercado do lazer e do entretenimento. Além disso, Gomes (2008) afirma que não se pode negar que "a demanda pela formação profissional no lazer sofre influências dessa situação (mercado em alta), pois muitos são atraídos pelas possibilidades lucrativas que essa área pode proporcionar" (p. 52). No cenário internacional, por exemplo, Bell et al. (2003) analisaram o contexto australiano e identificaram que o promissor mercado do lazer e entretenimento influencia a criação de cursos de formação neste campo, tanto na graduação quanto na formação técnica e continuada.

Vale destacar que a ampliação dos espaços de formação não está vinculada somente à expansão da indústria do entretenimento, mas a uma necessidade de atender as demandas da sociedade que, cada vez mais, se interessa por essa temática como campo de estudo e de intervenções. Além disso, destacamos o reconhecimento do lazer como direito fundamental para a construção da cidadania e para a melhoria da qualidade de vida dos cidadãos. 
Entendemos que existem possibilidades de trabalho no campo do lazer e que, para atender a essa demanda, é preciso investir na formação de profissionais para ocupar esses espaços. Como forma de suprir essa necessidade, surgem diversas iniciativas de formação, voltadas para qualificar profissionais que atuam no âmbito do lazer. No entanto, é preciso atentar-se para a qualidade dessa oferta, afinal, "na atualidade, existe uma tendência à comercialização das propostas de formação profissional, pois o lazer é focalizado como um filão do mercado que abre grandes possibilidades de ganhos" (Isayama, 2015, p. 15).

Em relação às possibilidades de formação profissional para atuar neste campo, apresentam-se diferentes modalidades: cursos de capacitação, de extensão, de qualificação, técnico, tecnológico, graduação e pós-graduação lato e stricto sensu. Essas opções variam em termos de carga horária e conteúdo, podendo, ainda, haver um aprofundamento sobre a temática através de projetos de pesquisa e extensão. Além disso, consideramos como espaço de formação profissional em lazer: grupos de pesquisa/estudo; eventos técnico-científicos; publicações e leitura de artigos da área, bem como a criação de listas de discussão e blogs, na internet.

Quanto às modalidades de ensino, percebemos a dificuldade em diferenciá-las, quando se tratavam das funções e das possibilidades de atuação dos egressos. Dúvidas em torno das diferenças entre a formação profissional em lazer ofertada por cursos técnicos e de graduação, bem como incertezas sobre a inserção desses profissionais no mercado de trabalho, nos motivaram a investigar tal realidade.

Nessa direção, destacamos os questionamentos que nortearam o presente estudo: em relação à inserção no mercado de trabalho, quais as funções assumidas pelos profissionais formados em cursos específicos de graduação em lazer? Em quais setores os egressos desses cursos têm desenvolvido suas ações?

Portanto, esse texto objetivou analisar a inserção no mercado de trabalho de profissionais formados em uma das possibilidades de oferta de formação no campo, que são os cursos de graduação específicos. Buscamos identificar e avaliar a inserção de egressos desses no mercado de trabalho, na tentativa de conhecer os setores de atuação aos quais estão vinculados e as funções que desenvolvem.

Ter conhecimento sobre esses fatores é uma forma de compreender a identidade dos profissionais do lazer, uma vez que ainda não há clareza sobre as peculiaridades de cada nível de formação, bem como sobre os espaços que esses profissionais ocupam no mercado de trabalho. Vale ressaltar que estudos envolvendo egressos de cursos de formação são 
Lima e Santos, C. A. N., \& Isayama. H. F. (set./dez. 2020). Formação e atuação profissional: egressos do curso de

considerados importantes por dois motivos: pela necessidade de avaliar os processos formativos ofertados e pela obtenção de informações sobre a situação dos sujeitos no mercado de trabalho.

\section{Fundamentação teórica: lazer e mercado de trabalho na contemporaneidade}

$\mathrm{Na}$ contemporaneidade, apresenta-se um novo modelo de mercado de trabalho, permeado por questões econômicas e tecnológicas que reorganizam as relações entre trabalho e trabalhador. Os princípios da flexibilidade norteiam os campos de atuação que, por sua vez, solicitam um perfil profissional com capacidade de resolução de problemas e de adaptação às mudanças.

Na direção da flexibilização, Pochmann (2010) chama a atenção para as concepções gerenciais e organizacionais e os novos tipos de trabalho, os quais não exigem tempo nem locais fixos. Nesse sentido, o autor estabelece diferenças entre trabalho material e imaterial. O primeiro é aquele "cujo esforço físico e mental resulta em alguma coisa física, concreta, tangível, palpável” (p. 32). No segundo, o resultado físico do trabalho não pode ser identificável e sua realização pode ocorrer em qualquer horário e local. Isso significa dizer que

Não é mais preciso haver um espaço determinado para a sua realização. Pela introdução e difusão das novas tecnologias de informação - o computador, o telefone e outras medidas está se trabalhando em qualquer lugar. O telefone celular corporativo faz com que as pessoas tomem decisões, administrem, executem em qualquer lugar (Pochmann, 2010, p. 33).

Vale ressaltar que essa extensão da jornada de trabalho, para além do local de serviço, acaba por afetar alguns direitos trabalhistas como, por exemplo, o aparecimento de doenças decorrentes da atividade profissional, mas que se manifestam fora do ambiente de trabalho e, por isso, não são consideradas doenças ocupacionais. Do mesmo modo, as horas extras realizadas fora do expediente, em atividades como responder a um e-mail do coordenador no dia de folga, na maioria das vezes, não são computadas e remuneradas. Questões da vida pessoal também são comprometidas, pois há que se considerar que esse modelo de trabalho acaba exigindo uma conexão constante, acarretando um aumento da jornada de trabalho e afetando a qualidade de vida dos trabalhadores. "Estamos vivendo uma situação de estarmos quase "plugados" vinte e quatro horas no trabalho. Adeus final de semana com a família, com esporte" (Pochmann, 2010, p. 34). 
Outra formatação para produção e comercialização de bens e serviços é a denominada Divisão Internacional do Trabalho. Trata-se de uma divisão geográfica de atividades e serviços entre países, como estratégia para a redução de custos da produção. Na maioria das vezes, essa configuração acontece quando um país oferece matéria-prima, mão de obra barata e benefícios, como a isenção de impostos, para a instalação de empresas ao país investidor e detentor da tecnologia produtiva.

Nessa direção, Pochmann (2015) adverte que

A Divisão Internacional do Trabalho parece referir-se mais à polarização entre a produção de manufatura, em parte nos países periféricos, e a produção de bens industriais de informação e comunicação sofisticados e de serviços de apoio à produção no centro do capitalismo. Nas economias semiperiféricas, a especialização em torno das atividades da indústria de transformação resulta, cada vez mais, proveniente da migração da produção de menor valor agregado e baixo coeficiente tecnológico do centro capitalista, que requer a utilização de mão de obra mais barata possível e qualificada não elevada, além do uso extensivo de matéria prima e de energia, em grande parte sustenta em atividades insalubres e poluidoras do ambiente, não mais aceitas nos países ricos (p. 122).

De acordo com o autor, essa formatação pode acarretar uma divisão desigual do trabalho, separando aqueles que criam daqueles que executam. Assim, os países que detém o investimento em pesquisas para desenvolvimento de novas tecnologias apropriam-se do poder de criação e planejamento e, consequentemente, dos maiores salários. Por outro lado, o processo de produção e execução é deslocado para países economicamente mais pobres, demandando ocupações tecnicamente mais simples e mais rotineiras e, consequentemente, salários mais baixos.

No mesmo viés da flexibilidade e da Divisão Internacional do Trabalho, o conceito de uberização vem sendo utilizado para definir novos modelos do trabalho contemporâneo. Vale ressaltar que essa terminologia não foi encontrada nas publicações acadêmicas que abordam a temática, mas em blogs ${ }^{1}$ e veículos de comunicação ${ }^{2}$ que elaboram artigos sobre negócios, mercado financeiro, recursos humanos e mundo corporativo. Esse termo foi inspirado na

\footnotetext{
${ }^{1}$ O Blog Passa Palavra, em fevereiro de 2017, publicou uma reflexão sobre essa temática, que se encontra disponível no seguinte endereço eletrônico: http://passapalavra.info/2017/02/110685. Acesso em: 01 mai. 2018.

${ }^{2}$ Um dos exemplos de veículo de comunicação que adotou tal terminologia foi a revista EXAME, que fez uma reportagem específica sobre o assunto. Disponível em: https://exame.abril.com.br/ negocios/mao-de-obrasofreu-uberizacao/. Acesso em 01 mai. 2018.
} 
empresa Uber $^{3}$, assim como o fordismo foi inspirado na empresa Ford e o toyotismo, na montadora de veículos Toyota.

Da configuração das empresas, passando pelas formas de controle ao gerenciamento e expropriação do trabalho, temos uma forma de regulação dos modos de produção, em que uma instituição, através de softwares e aplicativos, conecta o sujeito disposto a vender sua mão de obra ao público consumidor. O trabalhador, nesse caso, apesar de ser autônomo, está submetido às regras administrativas e produtivas superiores. Sobre esse modelo, Abílio (2018) alerta:

Podemos entender a uberização como um futuro possível para empresas em geral, que se tornam responsáveis por prover a infraestrutura para que seus "parceiros" executem seu trabalho; não é difícil imaginar que hospitais, universidades, empresas dos mais diversos ramos adotem esse modelo, utilizando-se do trabalho de seus "colaboradores just-in-time" de acordo com sua necessidade. Este parece ser um futuro provável e generalizável para o mundo do trabalho (p. 1).

Esse trabalho just-in-time é conhecido como "Contrato Zero Hora" e os trabalhadores são chamados de ultraflexíveis, visto que são contratados para exercer suas funções de acordo com a demanda e as necessidades da empresa, ou seja, ficam à disposição, embora só recebam pelas horas efetivamente trabalhadas. De acordo Sahuquillo (2018), esse modelo teve início em 2008, diante da crise financeira no Reino Unido. Como forma de ilustrar essa configuração ultraflexível, a autora descreve a seguinte cena:

É hora do almoço e, sentado em um banco perto das docas de Liverpool, Clive abocanha os últimos pedaços de seu sanduíche de frango caseiro. Na realidade, não tem pressa. Hoje, sua pausa para a refeição é extremamente longa. "Quatro horas! O chefe me disse que não precisa de mim durante este intervalo, mas que mais tarde terei outro par de horas de trabalho", explica, enquanto limpa as mãos em um pedaço de papel. Afirma que para ele não compensa voltar para casa, e que pretende passar o resto do tempo livre assistindo a corridas de cavalo na pequena casa de apostas Paddy Power. Há um ano, muitos dos dias são imprevisíveis assim para este homem de 46 anos, cabelo ralo e olhos pequenos e vivos. Trabalha em uma distribuidora com um "contrato de zero horas", uma modalidade na qual o empregador não garante ao trabalhador um mínimo de horas de carga por mês e, portanto, tampouco um salário mínimo (p. 1, grifo nosso)

Percebemos que essa nova formatação do mundo do trabalho vai além das questões de vínculos empregatícios e direitos trabalhistas. Outras dimensões da vida, como a família e o

\footnotetext{
${ }^{3}$ A Uber é uma empresa de tecnologia fundada em 2009, nos EUA, e que chegou ao Brasil em 2016. Através de um aplicativo, ela oferece serviço de transporte de passageiros, sendo que os motoristas prestadores do serviço são cadastrados e devem seguir determinadas regras e padrões. Além disso, os trabalhadores registrados devem destinar um percentual do que for arrecadado com as viagens efetivadas através do aplicativo para a empresa.
} 
lazer, também são afetadas. No trecho acima, por exemplo, o empregado Clive aproveita o “tempo disponível” para assistir corridas de cavalo, mas isso só foi possível porque ele havia sido informado de que voltaria ao trabalho apenas no final do dia. Porém, nesse modelo, nem sempre as pessoas sabem a escala de trabalho do dia, nem da semana e muito menos a escala do mês em que deverão estar presentes para realizar suas funções, ficando, assim, reféns das incertezas, o que afeta seu planejamento do tempo livre. Para Antunes (2006), as transformações no mundo do trabalho contemporâneo não repercutiram somente na materialidade dos trabalhadores, mas na subjetividade dos sujeitos, ou seja, "na sua forma de ser" (p. 23).

Com essas transformações ocorrendo em alta velocidade, Sennett (2009) chama a atenção para o perfil profissional que se espera destes "novos" trabalhadores. Para o autor, os novos tempos exigem qualidades como agilidade, flexibilidade e capacidade de adaptação às mudanças, já que as relações estabelecidas com o mercado serão de curto prazo.

Assim, o perfil profissional almejado na atualidade está distante de um modelo mecânico e engessado, calcado na reprodução e execução de tarefas. Diante desse cenário, acreditamos é fundamental uma formação voltada para habilitar profissionais capazes de mobilizar saberes para enfrentar as diferentes situações problemas que se apresentarão no decorrer do exercício da profissão.

Concordamos com Gomes (2006), que diz que os processos formativos em lazer devem privilegiar a associação entre "conhecimentos, habilidades, procedimentos, valores e atitudes. O modelo de competências evidencia uma preocupação em superar ações e comportamentos limitados à padronização e à repetição, que se esgotam em si mesmas" (p. 4).

O trabalho contemporâneo encontra-se margeado por questões econômicas e tecnológicas que acabam por reorganizar os sistemas de produção e a forma como os sujeitos se relacionam com o tempo e com o espaço de trabalho. No entanto, é preciso perguntar se essas novas relações ocupacionais aplicam-se a todos os trabalhadores. No caso específico desse artigo, procuramos estabelecer relações entre formação e atuação profissional em lazer, tendo em vista as características do mercado de trabalho contemporâneo.

Dessa forma, vale recordar que o campo de atuação profissional em lazer pode ser caracterizado a partir de duas dimensões: dos setores da sociedade e dos vínculos empregatícios. Essas dimensões, apesar de se relacionarem entre si, serão abordadas de forma separada, para uma melhor compreensão. 
Em relação à primeira dimensão, de acordo com a Constituição da República Federativa do Brasil, de 1988, nossa sociedade está dividida em três setores: o primeiro setor, também denominado de setor público, é representado pelo Estado; o segundo setor é representado pelas instituições privadas e o terceiro setor abriga as associações e entidades sem fins lucrativos. Podemos dizer que os três setores são espaços possíveis de atuação para aqueles que desenvolvem atividades profissionais no campo do lazer.

No primeiro setor estão as instituições públicas da esfera municipal, estadual e federal que oferecem vivências de lazer para a população, através de ações de políticas públicas. O Programa Esporte e Lazer na Cidade (PELC) ${ }^{4}$, por exemplo, é uma dessas políticas públicas que abriga profissionais que trabalham no campo do lazer. No setor privado, estão as empresas que vendem serviços ou produtos visando lucro. As possibilidades de atuação nesse âmbito concretizam-se em hotéis, parques temáticos, clubes, empresas de eventos, campings, cruzeiros marítimos, dentre outros. Incluem-se nesse segundo campo, as entidades patronais, como o Serviços Social do Comércio (SESC) e Serviço Social da Indústria (SESI). O terceiro setor diz respeito às entidades organizadas pela sociedade civil, de acordo com suas necessidades. Esse campo é constituído, por exemplo, por Organizações Não Governamentais (ONGs) e Associações de classes. Para que esses setores ofertem atividades de lazer, é preciso que contem com profissionais que elaborem, coordenem, executem e avaliem tais vivências.

No que diz respeito à segunda dimensão, quando inseridos nesses setores, os vínculos empregatícios com os profissionais se estabelecem de diferentes formas: freelancer contratação esporádica, sem vínculos empregatícios; concursado - cargo permanente no setor público; formal - prestação de serviço com vínculos empregatícios; autônomo - prestação de serviço independente, sem vínculos empregatícios; terceirizado - composição do quadro de prestadores de serviço, possuindo ou não vínculos empregatícios.

Werneck (2001), Melo e Alves Júnior (2012) e Stoppa (2001) corroboram o pensamento de que o mercado informal acaba por abarcar parte das pessoas que trabalham no campo do lazer. Afinal, a inexistência de vínculo empregatício é uma opção considerada viável para

\footnotetext{
${ }^{4}$ O Programa Esporte e lazer da Cidade (PELC), desenvolvido por intermédio da Secretaria Nacional de Esporte, Educação, Lazer e Inclusão Social (Snelis), proporciona a prática de atividades físicas, culturais e de lazer que envolve todas as faixas etárias e pessoas com deficiência, estimula a convivência social, a formação de gestores e lideranças comunitárias, favorece a pesquisa e a socialização do conhecimento, contribuindo para que o esporte e lazer sejam tratados como políticas e direitos de todos. Informações disponíveis em: http://www.esporte.gov.br/index.php/institucional/esporte-educacao-lazer-e-inclusao-social/esporte-e-lazer-dacidade/programa-esporte-e-lazer-da-cidade-pelc. Acesso em 01 jun. 2018
} 
pequenas empresas ou para aquelas que só contratam trabalhadores temporários, como hotéis em período de alta temporada. Isso porque as grandes empresas não têm como escapar dos encargos trabalhistas, já que necessitam de empregados atuantes todo o ano e não apenas em determinadas épocas (Werneck, 2001).

Apesar de existirem ações de lazer permanentes, que não se limitam aos finais de semana, férias e feriados, o caráter sazonal do lazer pode interferir no processo de contratação de profissionais para atuarem nesse campo. Dessa forma, as oportunidades de trabalho podem assumir o modelo just-in-time,,$^{5}$ que obriga que os profissionais desenvolvam suas funções apenas quando são convocados, ficando à mercê da demanda do mercado.

Outro ponto a ser destacado diz respeito às peculiaridades da formação e da atuação no âmbito do lazer, afinal trata-se de uma área que possibilita a atuação de profissionais com diferentes formações (turismólogos, profissionais de educação física, pedagogos, arte educadores, dentre outros), que dividem espaço com profissionais com formação específica em lazer, formados em diferentes níveis: nas instituições de ensino técnico, graduação e pósgraduação. Nesse sentido, consideramos importante a interdisciplinaridade, visto que a atuação no campo configura-se como um fenômeno que necessita da correlação de competências, saberes e habilidades específicos de diferentes áreas, no intuito de contemplar os variados interesses culturais vivenciados no lazer.

Vale lembrar que, para atuar no campo do lazer, não é exigida, legalmente, nenhuma formação específica. A única orientação nesse sentido vem da Classificação Brasileira de Ocupações $(\mathrm{CBO})^{6}$, que propõe que, para atuar no campo do lazer, a escolaridade mínima deve ser ensino médio. Não obstante, ainda é recorrente a ideia de que, para atuar nessa área, não é preciso formação, bastando ter um dom. Por essa perspectiva, a formação torna-se dispensável, pois outras características, como extroversão, beleza e carisma, são mais valorizadas (Stoppa, 2001).

Diante do exposto, atuam no âmbito do lazer os seguintes perfis: pessoas sem formação acadêmica, profissionais com formação acadêmica específica em lazer e profissionais com formação acadêmica em diferentes cursos. Acreditamos na importância da formação acadêmica

\footnotetext{
${ }^{5}$ Modo de trabalho denominado de "Contrato Zero Hora", em que os trabalhadores recebem a denominação de ultraflexíveis. Eles são contratados para exercerem suas funções de acordo com a demanda e as necessidades da empresa, ou seja, ficam à disposição, porém, só recebem pelas horas efetivamente trabalhadas.

${ }^{6}$ A Classificação Brasileira de Ocupações (CBO), instituída pela portaria ministerial no ${ }^{\circ} .397$, de 9 de outubro de 2002, tem por finalidade a identificação das ocupações no mercado de trabalho, para fins classificatórios junto aos registros administrativos e domiciliares. Disponível em: www.mtecbo.gov.br. Acesso em: 05 abr. 2019.
} 
para o profissional que atua no âmbito do lazer, afinal as atribuições inerentes à atuação não se resumem à execução de tarefas ou à concretização de uma programação preestabelecida.

Entendemos que esse profissional também pode assumir as funções de planejamento, organização, coordenação, supervisão e avaliação de vivências e projetos de lazer. Para tanto, demanda-se competência técnica, sensibilidade e compromisso político, como embasamento de uma intervenção crítica na busca da emancipação dos sujeitos envolvidos. No entanto, não quer dizer que, para assumir essa postura, seja obrigatória uma formação acadêmica.

\section{Metodologia}

Para a realização dessa pesquisa, escolhemos a Escola de Artes, Ciências e Humanidades da Universidade de São Paulo - Campus Leste (EACH), que oferta o curso de graduação em Lazer e Turismo. A escolha dessa instituição deveu-se ao fato de ser uma instituição pública, que oferta o curso na modalidade presencial e de maneira regular, atendendo, assim, os critérios estabelecidos para a investigação. Além disso, a referida instituição é a mais antiga, em relação às demais, na oferta de cursos específicos de lazer, no Brasil, o que amplia as chances de encontrar maior quantidade de egressos.

A estratégia escolhida para a coleta de dados combinou as pesquisas bibliográfica, documental (projeto pedagógico do curso e site da instituição) e de campo. Após aprovação pelo Comitê de Ética em Pesquisa ${ }^{7}$, iniciamos a pesquisa de campo com egressos do curso. Foram considerados egressos aqueles que estão habilitados a ingressar no mercado de trabalho e que concluíram todas as atividades formativas previstas no plano de curso, como disciplinas curriculares, estágios, horas acadêmicas, trabalho de conclusão de curso, além da necessidade de colar grau.

Os dados dos egressos da EACH/USP foram obtidos mediante a parceria com a Comissão de Pesquisa $(\mathrm{CP})$ e com o Serviço de Apoio à Gestão dos Sistemas de Informação (SVAGESI), da Universidade de São Paulo (USP). Tais órgãos forneceram os nomes dos ex alunos, com os respectivos e-mails e informaram o ano de conclusão do curso de cada egresso. Vale ressaltar que nos deparamos com dados desatualizados, o que nos levou a adotar a estratégia de contato via redes sociais. Nesse caso, o Facebook foi a ferramenta utilizada, sendo que, após nossa inserção no grupo virtual "Lazer e Turismo - EACH-USP”, publicamos a

\footnotetext{
${ }^{7}$ Número do parecer de aprovação do COEP: CAAE 59242716.1.0000.5149
} 
informação de que estávamos realizando pesquisa com egressos e que os interessados deveriam entrar em contato para participarem. Com essa "divulgação", conseguimos o contato de 57 (cinquenta e sete) pessoas, sendo que alguns nos contataram diretamente e outros foram $\operatorname{marcados}^{8}$ por colegas.

A partir das informações advindas da USP, verificamos a existência do total de 631 (seiscentos e trinta e um) egressos da graduação em Lazer e Turismo da EACH. A expectativa inicial, de acordo com informações prévias, como data de fundação do curso, duração e número de vagas ofertadas, apontava para uma amostra de, aproximadamente, 1.080 egressos. Esse cálculo considerou o ano de 2016 como limite da amostra. No entanto, essa diferença, de 1080 para 630 ex-alunos, é decorrente de fatores como abandono de curso; existência de algum tipo de pendência que impediu a conclusão do curso, bem como o não preenchimento completo do número de vagas ofertadas pela instituição.

Com os e-mails atualizados, os egressos foram convidados a participar da pesquisa, por meio do preenchimento de um questionário online, que foi elaborado com o uso do aplicativo "formulários", do Google App. ${ }^{9}$ O questionário foi dividido em 8 seções, com questões relativas a dados pessoais (idade, cor, sexo e naturalidade); dados da formação acadêmica (ano de ingresso e conclusão do curso e demais formações acadêmicas) e dados profissionais (inserção no mercado de trabalho, campo de atuação, funções desenvolvidas, renda, carga horária trabalhada, vínculo empregatício).

Assim como Barros e Lehfeld (2000), entendemos que o questionário configura-se como um importante instrumento de coleta de dados, pois apresenta vantagens como: abranger um maior número de pessoas e de informações, não necessitando de um longo espaço de tempo; facilitar a tabulação e o tratamento dos dados obtidos, em caso de amostras significativas; e oferecer tempo suficiente para que os sujeitos pesquisados possam refletir sobre as questões e respondê-las adequadamente.

Além disso, optamos pela coleta de dados através do ambiente virtual, por considerá-la um meio seguro, rápido, de baixo custo e de grande alcance. Nesse sentido, corroboramos as ideias de Aaker, kumar e Day (2007), que elencam algumas vantagens dos questionários online:

\footnotetext{
${ }^{8}$ Expressão utilizada na linguagem virtual. Trata-se de um recurso das redes sociais em que uma pessoa menciona outra com o intuito de compartilhar alguma foto, vídeo ou informação.

${ }^{9}$ O Google App oferece, entre outros, o aplicativo "formulários", que permite elaborar e compartilhar via e-mail, questionários com perguntas abertas e fechadas. As respostas são enviadas automaticamente para o e-mail do responsável pela pesquisa.
} 
eles podem ser enviados quantas vezes forem necessárias, com maior rapidez; há uma velocidade no recebimento das respostas; além disso, podem ser respondidos de acordo com a conveniência e o tempo disponível do entrevistado.

Todos os voluntários, ao terem acesso ao questionário, visualizavam de imediato o Termo de Consentimento Livre e Esclarecido (TCLE) que, além de explicar o objetivo e os métodos da pesquisa, solicitava a permissão para utilização dos dados coletados.

Do total de 630 (seiscentos e trinta) egressos da $\mathrm{EACH}$, foi possível enviar 546 (quinhentos e quarenta e seis) questionários online. Essa perda de questionários diz respeito a problemas como e-mail inexistente nos registros oficiais ou e-mails que retornaram. Do montante de 546 (quinhentos e quarenta e seis) questionários enviados, 73 (setenta e três) foram respondidos pelos ex alunos da graduação em Lazer e Turismo. Em percentuais, 13,4\% dos egressos contatados aderiram à pesquisa.

Com os questionários respondidos, organizamos os dados, com o apoio do Software Statistical Package for the Social Sciences (SPSS) e, para alimentar o SPSS, foi preciso numerar e cadastrar as questões fechadas no sistema. A partir disso, foi possível visualizar gráficos e tabelas com cada categoria e estabelecer os cruzamentos de dados.

As questões abertas foram organizadas e analisadas mediante a técnica de análise de conteúdo, proposta por Bardin (2011). A análise de conteúdo consiste em três etapas: a) a préanálise, em que acontece a organização do material; b) a fase de exploração do material, onde o material levantado é codificado, classificado e categorizado; c) a etapa de tratamento dos resultados, em que o pesquisador ou a pesquisadora transformarão os dados brutos em dados significativos e válidos.

Dessa forma, reunimos as respostas abertas dos voluntários, observando aquelas que se aproximavam e se repetiam. Num segundo momento, separamos as informações em 3 categorias, a saber: especificidades da atuação profissional do graduado em lazer; processo formativo em lazer no ensino superior; mercado de trabalho no campo do lazer.

\section{Resultados: os egressos da each e a inserção no mercado de trabalho}

A criação do curso de Lazer e Turismo da EACH decorreu de uma pesquisa diagnóstica realizada previamente à sua implementação. Tal pesquisa endossou a crescente do mercado e a consequente necessidade de profissionais para trabalharem nesses segmentos. 
A criação do curso da EACH justificou-se pela importância que o lazer tem assumido na sociedade, carecendo, portanto, de estudos que o considerem como uma necessidade humana e um direito social. Essa preocupação está expressa no Projeto Pedagógico do curso. No site da instituição, por sua vez, o curso é anunciado como algo promissor e destacam-se os megaeventos como uma das justificativas da expansão do mercado de trabalho.

Percebemos que as justificativas empregadas para a criação do curso corroboram as ideias de Isayama (2015), Marcellino (2010), Gomes e Melo (2003), Bell et al. (2003) e Gomes (2008), ao definirem o lazer como um campo promissor e rentável, que requer trabalhadores específicos. No entanto, coube verificar se essa alta empregabilidade esperada foi concretizada ao final do processo formativo. Vimos, anteriormente, que o mercado de trabalho assume uma nova configuração, consequência das mudanças nos processos de trabalho decorrentes da nova dinâmica econômica, portanto coube avaliar como o mercado do lazer está respondendo a essa realidade.

Tendo como data limite o ano de 2016, para identificar e selecionar a amostra de egressos do curso superior em Lazer e Turismo, desde o início do curso, em 2005, formaramse 18 turmas, sendo 9 no turno vespertino e 9 no noturno. Assim, num total de 1.080 matriculados, 630 concluíram o curso, ou seja, 58,33\%. Esse índice favorável de concluintes pode estar ligado ao fato da USP ser referência nacional e internacional em educação, embora não devamos ignorar as questões socioeconômicas que influenciam o acesso e a permanência no ambiente escolar.

Apesar do considerável número de concluintes do curso, alcançando quase $60 \%$ do total de alunos, existe uma preocupação em relação à desvinculação, à evasão e ao tempo de formação, como aponta o parecer $^{10}$ de reconhecimento do curso, publicado em 2016. Tal parecer registra que há indicativos de um número de egressos menor, comparado à oferta de vagas (São Paulo, 2016).

Em relação à caracterização do perfil dos egressos do curso da $\mathrm{EACH}$, destacamos algumas categorias como: sexo, idade e cor.

\footnotetext{
${ }^{10}$ Processo 2016.1.7277.1.3 e 2016.1.7677.1.1
} 
Tabela 1 - Caracterização da amostra da EACH em relação ao sexo e à idade

\begin{tabular}{l|l|c|c|c|c|c|c}
\hline \multirow{2}{*}{} & \multicolumn{5}{c|}{ Idade } & Total \\
\cline { 2 - 8 } & $\mathbf{2 0}$ a 24 & $\mathbf{2 5}$ a 29 & $\mathbf{3 0}$ a 34 & $\mathbf{3 5}$ a 39 & $\mathbf{4 0}$ a 44 & \\
\hline \multirow{2}{*}{ Sexo } & $\begin{array}{l}\text { Sexo } \\
\text { feminino }\end{array}$ & 11 & 29 & 13 & 2 & 1 & 56 \\
\cline { 2 - 8 } & $\begin{array}{l}\text { Sexo } \\
\text { masculino }\end{array}$ & 0 & 11 & 3 & 1 & 2 & 17 \\
\hline Total & 11 & 40 & 16 & 3 & 3 & 73 \\
\hline
\end{tabular}

Fonte: Organizado pelos autores a partir das respostas dos egressos.

Ressaltamos que o ingresso na USP mediante sistema de cotas só foi implementado no processo seletivo de 2017. Assim, nenhum egresso do curso da EACH que fez parte do grupo pesquisado ingressou por meio de cotas sociais e raciais. Esse fator pode explicar o alto índice de sujeitos brancos, como se pode observar no Gráfico 1:

Gráfico 1 - Percentual de egressos da EACH por cor

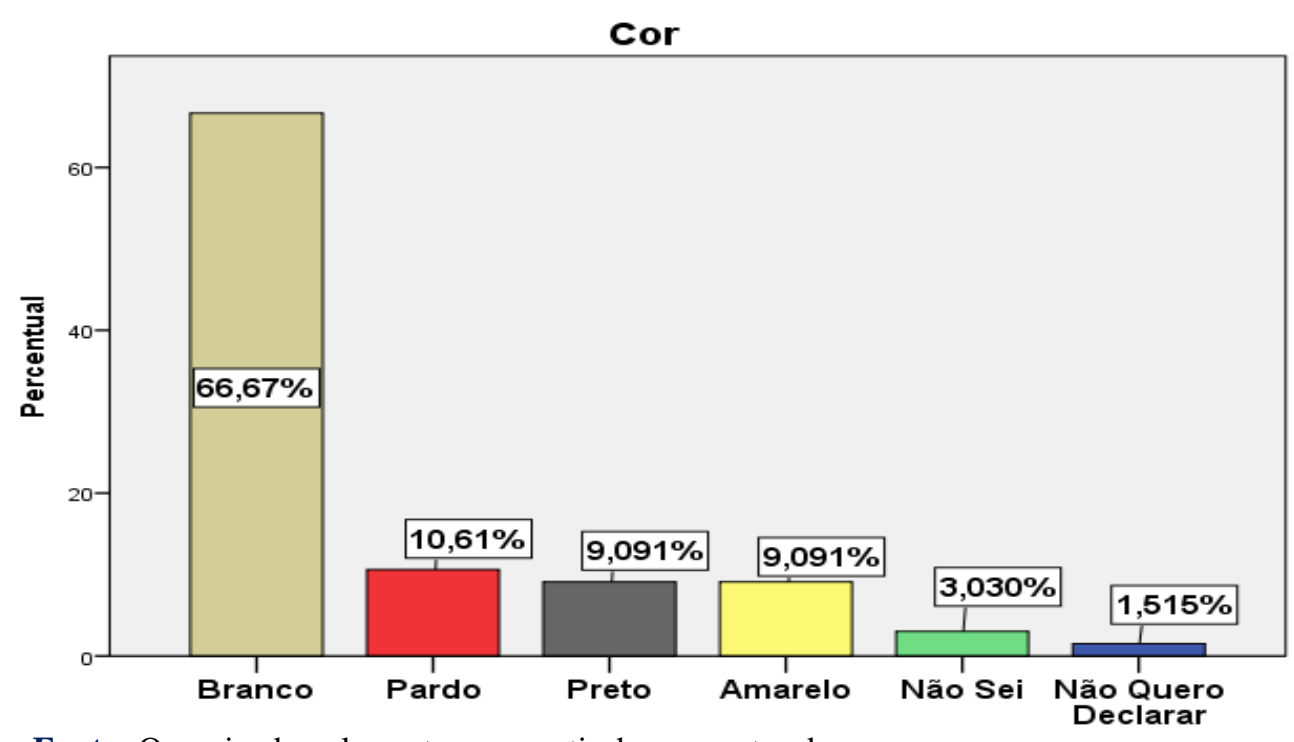

Fonte: Organizado pelos autores a partir das respostas dos egressos.

Além disso, o último censo demográfico brasileiro (Instituto Brasileiro de Geografia e Estatística [IBGE], 2010) apontou uma diferença quanto ao acesso aos níveis de ensino pela população negra, quando comparada com a branca. De acordo com os dados do instituto, no grupo de pessoas entre 15 a 24 anos que frequentava um curso de nível superior, apenas 12,8\% 
eram pretos; $13,4 \%$ eram pardos e $31,1 \%$ eram brancos.

Somado a isso, ainda de acordo com os dados do censo, o estado de São Paulo é o $24^{\circ}$ na classificação, visto que $34,6 \%$ das pessoas que se autodeclaram pardos e pretos. Dessa forma, é possível inferir que ao menos três fatores que podem ter influenciado os percentuais: o fato de não haver ingresso através de cotas, até o ano de recorte da pesquisa; o fato de São Paulo possuir um maior percentual de pessoas que se autodeclaram brancas e o fato de pesquisas apontarem para um maior acesso de brancos ao ensino superior.

A formação acadêmica e a inserção no mercado de trabalho foram pontos abordados no questionário e buscaram compreender, entre outros, os motivos da escolha do curso de Lazer e Turismo, bem como trazer informações sobre o campo de atuação dos egressos.

Os dados coletados apontam que a diversidade de áreas de atuação que esse campo proporciona foi o principal fator motivacional para a escolha do curso, de acordo com seus egressos, como vemos na Tabela 2:

Tabela 2 - Motivos que levaram os egressos da EACH a escolherem o curso

\begin{tabular}{|c|c|c|c|}
\hline & \multicolumn{2}{|c|}{ RESPOSTAS } \\
\hline & & Frequência & Percentual \\
\hline \multirow{6}{*}{$\begin{array}{c}\text { Influência para escolha } \\
\text { do curso } \\
(\mathrm{EACH})\end{array}$} & $\begin{array}{l}\text { Vocação para a área do } \\
\text { lazer e do turismo }\end{array}$ & 30 & $31,6 \%$ \\
\hline & $\begin{array}{c}\text { Ter trabalhado na área do } \\
\text { lazer e do turismo antes de } \\
\text { se formar }\end{array}$ & 10 & $10,5 \%$ \\
\hline & $\begin{array}{l}\text { A possibilidade de } \\
\text { melhorar a renda salarial }\end{array}$ & 5 & $5,3 \%$ \\
\hline & $\begin{array}{l}\text { A diversidade de áreas de } \\
\text { atuação que o campo do } \\
\text { lazer e do turismo } \\
\text { proporciona }\end{array}$ & 38 & $40,0 \%$ \\
\hline & $\begin{array}{c}\text { Facilidade dos concluintes } \\
\text { desse curso em conseguir } \\
\text { emprego }\end{array}$ & 4 & $4,2 \%$ \\
\hline & $\begin{array}{c}\text { Não ter sido aprovado/a em } \\
\text { outro curso de sua } \\
\text { preferência }\end{array}$ & 8 & $8,4 \%$ \\
\hline
\end{tabular}

Fonte: Organizado pelos autores, com base nas respostas dos egressos. 
Como apresentado, as expectativas dos alunos antes do início da formação vão ao encontro das perspectivas do projeto pedagógico do curso, que afirma que o mercado do lazer e do turismo está em voga. Apesar disso, apenas 4,2\% dos egressos acreditavam que, após a conclusão do curso, teriam facilidade em conseguir emprego.

Ao serem questionados se estão atuando no campo, a maioria afirmou que não está exercendo a profissão, como podemos verificar na Tabela 3.

Tabela 3 - Egressos que estão trabalhando no campo do lazer e do turismo

\begin{tabular}{l|c|c}
\hline \multirow{2}{*}{$\begin{array}{l}\text { Sim, estou trabalhando na área } \\
\text { Não estou trabalhando na área }\end{array}$} & Frequência & Percentual \\
\cline { 2 - 3 } \begin{tabular}{l} 
Total \\
\cline { 2 - 3 }
\end{tabular} & 35 & 47,9 \\
\cline { 2 - 3 } & 73 & $\mathbf{5 2 , 1}$ \\
\hline
\end{tabular}

Fonte: Organizado pelos autores, com base nas respostas dos egressos.

Dessa forma, identificamos que mais da metade dos egressos $(52,1 \%)$ não está trabalhando no campo, por motivos diversos, conforme a Tabela 4.

Tabela 4 - Motivos pelos quais os egressos da EACH não estão exercendo a profissão

\begin{tabular}{c|c|c|c}
\hline \multicolumn{2}{c}{} & \multicolumn{2}{c}{ RESPOSTAS } \\
\cline { 2 - 4 } & Frequência & Percentual \\
\hline \multirow{2}{*}{$\begin{array}{c}\text { Porque não está } \\
\text { trabalhando na área }\end{array}$} & $\begin{array}{c}\text { Não se identificou com a } \\
\text { área de atuação }\end{array}$ & 10 & $14,9 \%$ \\
\cline { 2 - 4 }$(\mathbf{E A C H})$ & $\begin{array}{c}\text { Não teve oportunidade de } \\
\text { trabalho }\end{array}$ & 11 & $16,4 \%$ \\
\cline { 2 - 4 } & $\begin{array}{c}\text { Renda salarial aquém do } \\
\text { que imaginava }\end{array}$ & 21 & $31,3 \%$ \\
\cline { 2 - 4 } & $\begin{array}{c}\text { Preferiu investir em uma } \\
\text { nova carreira }\end{array}$ & 19 & $28,4 \%$ \\
\cline { 2 - 4 } & O mercado está saturado & 6 & $9,0 \%$ \\
\hline
\end{tabular}

Fonte: Organizado pelos autores, com base nas respostas dos egressos.

Outros motivos também foram identificados como: estar se dedicando à pós-graduação 
Strictu Senso (2); ter se mudado para o exterior (1), achar que a área não é valorizada (1) ou, até mesmo, questões de saúde (1).

O fato de a maioria dos egressos não estar exercendo a profissão não necessariamente está ligado a uma possível falta de vagas de emprego no setor, mas pode se relacionar à demanda de mão de obra disponível para atuar. Ou seja, não estamos questionando se lazer e turismo são "fílões" do mercado de trabalho e se geram possibilidades de emprego, porém, há que se contestar que as vagas não têm sido preenchidas por profissionais com formação específica na área. Afinal, para atuar no campo, os profissionais podem ter formações que variam do ensino médio ao ensino superior. Observamos que, conforme disposto na Tabela 5, somente 9\% dos pesquisados consideram que o mercado está saturado e 16,4\% afirmam não ter tido uma oportunidade de emprego. Por outro lado, a maioria, 31,3\%, dize não atuar por que os salários não são compatíveis com o que esperavam, ou seja, a não atuação dos egressos no campo em que se formaram pode estar mais relacionada à desvalorização da área do que à falta de oportunidades.

Em estudo semelhante realizado na África do Sul, Schreck e Reitsma (2019) identificaram que, nos últimos 10 anos, a taxa de desemprego de profissionais egressos de cursos de formação em lazer aumentou em 4\%. De acordo com os autores, a não inserção no campo específico de atuação relaciona-se com a baixa atividade econômica atual do país e com a incompatibilidade existente entre a formação ofertada e as necessidades do mercado de trabalho.

Nossos resultados também corroboram o estudo de Bell et al. (2003), que aponta que a alta competitividade no setor está interferindo na empregabilidade. Os autores destacam que os egressos de curso de formação específica passam a concorrer com profissionais de outros setores, como educação, saúde, marketing e arte.

Vale ressaltar que, apesar desse estudo ser voltado para à análise do campo do lazer, o curso de graduação escolhido abrange lazer e turismo, ou seja, as análises extrapolam o campo predeterminado. Além disso, consideramos que o lazer é um campo que pode pertencer ao campo do turismo. Por isso, buscamos dados do Sistema de Informações sobre o Mercado de Trabalho no Setor Turismo (SIMT) que, através da parceria entre Ministério do Turismo (MTur) e Instituto de Pesquisa Econômica Aplicada (IPEA), reuniu dados sobre o setor, mostrando, por exemplo, que 2,04 milhões de ocupações no Brasil concentram-se no campo do turismo. Desse montante, 1,03 milhões (51\%) são de empregos formais e 1,01 milhões (49\%) 
são de empregos informais (Sistema de Informações sobre o Mercado de Trabalho [SIMT], 2014).

Apesar das oportunidades que o campo oferece, ao analisar as falas dos egressos, notamos uma certa decepção com a área em que se formaram. Os egressos lamentam a falta de reconhecimento da profissão, as expectativas não atendidas e a concorrência com outros profissionais. As respostas à questão "Você recomendaria o curso superior de Lazer e Turismo? Por quê?" ilustra esse descontentamento:

Não acredito que seja necessária uma graduação de 4 anos para atuar na área. Além disso, o mercado não reconhece e não valoriza a formação acadêmica (Egresso 12).

Não acho que o curso não tenha sido válido, mas tenho plena convicção de que ele não é uma exigência no mercado de turismo brasileiro. Vejo profissionais das mais diferentes áreas sendo contratados para trabalhar no setor, o que desvaloriza o profissional formado na área. Como estou estudando Administração de empresas, vejo como o curso de lazer e turismo é desfalcado nas áreas de gestão, contabilidade, marketing etc. (Egresso 52).

A insatisfação presente na fala de alguns egressos é consequência do caráter interdisciplinar do campo e nos faz refletir sobre a necessidade de formação específica em lazer. O estudo de Henderson (2011) instiga justamente a esse debate, ao apontar a crise dos estudos do lazer no cenário norte-americano. De acordo com a autora, pesquisadores da área que antes faziam parte da mesma organização, a National Recreation and Park Association, distanciaram-se quando a instituição passou a focar suas pesquisas no campo das políticas públicas em lazer. Os demais pesquisadores que se interessam por outras temáticas do lazer voltaram-se para suas áreas de origem, como o esporte e turismo, por exemplo. A partir desse cenário, a autora reflete sobre as possibilidades dos estudos do lazer ora como campo específico ora como pertencente a seu campo de origem. Acreditamos que, no Brasil, tais questionamentos começam a surgir, principalmente em relação aos cursos de formação específica.

Retomando as análises sobre os egressos da EACH, cabe ressaltar que o fato de alguns egressos estarem atuando ou não no campo não necessariamente recai sobre a indicação do curso, ou seja, no total de 38 pessoas que não exercem a profissão, 20 recomendam o curso e 18 não recomendam. Da mesma forma, 5 ex alunos, mesmo estando empregados no setor, não recomendam o curso que fizeram, como mostra a Tabela 5. 
Tabela 5 - Relação entre egressos que exercem a profissão e a recomendação do curso da $\mathrm{EACH}$

\begin{tabular}{l|l|c|c|c}
\hline \multicolumn{2}{c|}{} & \multicolumn{2}{c|}{ Você Recomenda o Curso? } & \multirow{2}{*}{ Total } \\
\cline { 3 - 4 } \multicolumn{2}{c|}{} & Sim & Não & \\
\hline $\begin{array}{c}\text { Está } \\
\text { trabalhando } \\
\text { no com lazer e } \\
\text { turismo? }\end{array}$ & Não estou trabalhando na área & 20 & 18 & 38 \\
\hline $\begin{array}{l}\text { Total } \\
\text { Sim, estou trabalhando na área }\end{array}$ & 30 & 5 & 35 \\
\cline { 3 - 4 } & & 50 & 23 & 73 \\
\hline
\end{tabular}

Fonte: Organizado pelos autores com base nas respostas dos egressos.

Aqueles que dizem recomendar o curso de Lazer e Turismo da EACH atribuíram-lhe fatores positivos, como a excelência do corpo docente e da instituição; o amplo campo de atuação que o mercado de lazer e turismo proporciona; o desenvolvimento do olhar crítico e o aprofundamento teórico sobre a temática.

Pois o curso, além de fornecer embasamento teórico, possibilitou o desenvolvimento do senso crítico necessário para uma melhor atuação profissional (Egresso 57).

Para quem gosta da área, é uma oportunidade de conhecer excelentes docentes e profissionais, além da oportunidade de nortear campos que você tenha interesse em atuar (Egresso 19).

Um ponto que merece destaque diz respeito à dualidade teoria e prática, uma vez que alguns respondentes consideram que o curso aprofunda as questões teóricas e se distancia da realidade do mercado de trabalho:

É interessante para a área acadêmica, mas para mercado de trabalho não se aprende muito além do que poderia ser aprendido sozinho ou com a prática em um trabalho na área (Egresso 25).

Porque depende muito das suas expectativas, pois o curso de graduação é desenvolvido em caráter, prioritariamente, teórico. O que causa conflito com o mercado de trabalho e posteriores enquadramentos a sistemas e técnicas. Contudo, se o intuito é seguir carreira em pesquisa, eu indicaria (Egresso 68).

O distanciamento entre as propostas dos cursos de formação e as necessidades do mercado de trabalho em lazer é apontado no estudo de Bell et al. (2003), que identificaram que 
os egressos dos cursos de formação em lazer, na Austrália, qualificam-se mais no exercício da profissão do que na formação inicial e na pós-graduação. No entanto, o conhecimento da educação formal não é desprezado e também é reconhecido como importante.

Entendemos que o processo formativo não deve ser caracterizado pela dicotomia teoria e prática, afinal não concebemos o fazer sem que haja reflexão. Além disso, o projeto pedagógico do curso da $\mathrm{EACH}$ não corrobora esse pensamento dual e alguns alunos reconhecem essa importância: "A teoria também é importante para que a prática faça sentido" (Egresso 3).

Além disso, alguns ex-alunos consideram que o curso da EACH é voltado para a formação de pessoas que desejam dar prosseguimento à carreira acadêmica, conforme destacado em alguns comentários:

Se tiver a intenção de seguir na área de planejamento e acadêmica é um curso muito bom (Egresso 1).

Porque (no meu período) ele foi muito mais voltado ao aluno se tornar um pesquisador, o que a grande maioria da sala não desejava. Coisas técnicas e de suma importância não nos foram apresentadas (Egresso 62).

É importante não confundir o aprofundamento teórico e o incentivo à pesquisa com formação de pesquisadores. O processo de formação profissional reúne, entre outros elementos, a pesquisa, como um fator que promove a reflexão sobre a própria prática, favorecendo o desenvolvimento da autonomia dos sujeitos, como apontam Schön (2000) e Tardiff (2008). Além disso, o processo de formação deve transcender aspectos meramente técnicos, valorizando aspectos intelectuais e de comportamento (Perrenoud, 2002; Gondim, 2008). Portanto, consideramos importante não valorizar um conhecimento em detrimento do outro, visto que, na atuação profissional, teoria e prática não se encontram desvinculadas (Perez Gomez, 1992).

Por um outro lado, é importante considerar que a possibilidade de construir uma carreira acadêmica a partir de um curso superior é mais tangível, uma vez que o aprofundamento de diferentes temáticas é oportunizado pela maior duração do curso, quando comparado ao tempo de formação dos cursos técnicos. Isso não quer dizer que, no último, não haja incentivo à pesquisa, mas um dos caminhos de um curso superior é a possibilidade de ingressar diretamente em uma pós-graduação. Nesse sentido, mais de 67,12\% dos egressos da EACH afirmam possuir outra formação acadêmica, como podemos verificar no Gráfico 2. 
Gráfico 2 - Percentual de egressos da EACH que possuem outra formação

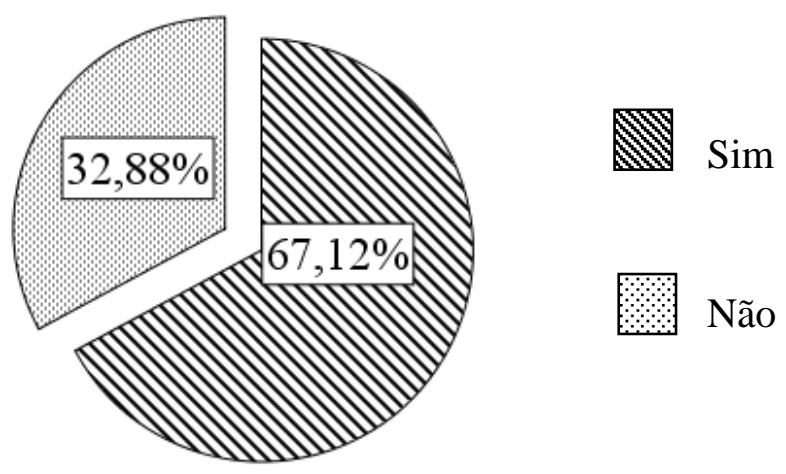

Fonte: Organizado pelos autores com base nas respostas dos egressos.

Essas outras formações as quais os participantes dedicaram-se variam de curso técnico à pós-graduação stricto sensu, como retrata a Tabela 6 .

Tabela 6 - Relação de demais formações que os egressos da EACH possuem

\begin{tabular}{|c|c|c|c|}
\hline & \multicolumn{2}{|c|}{ RESPOSTAS } \\
\hline & & Frequência & Percentual \\
\hline \multirow{8}{*}{$\begin{array}{l}\text { Outra formação } \\
\text { acadêmica que possui } \\
\text { (EACH) }\end{array}$} & Curso Técnico & 19 & $19,2 \%$ \\
\hline & Graduação & 10 & $10,1 \%$ \\
\hline & Graduação em Andamento & 18 & $18,2 \%$ \\
\hline & Pós-graduação Lato Sensu & 18 & $18,2 \%$ \\
\hline & $\begin{array}{l}\text { Pós-graduação Lato Sensu em } \\
\text { andamento }\end{array}$ & 3 & $3,0 \%$ \\
\hline & Pós-graduação Stricto Sensu & 4 & $4,0 \%$ \\
\hline & $\begin{array}{l}\text { Pós-graduação Stricto Sensu em } \\
\text { andamento }\end{array}$ & 9 & $9,1 \%$ \\
\hline & $\begin{array}{l}\text { Não possuo outra Formação } \\
\text { Acadêmica }\end{array}$ & 18 & $18,2 \%$ \\
\hline
\end{tabular}

Fonte: Organizado pelos autores, com base nas respostas dos egressos.

Somando as pós-graduações lato e stricto sensu concluídas ou em andamento, o percentual supera $34 \%$. O perfil acadêmico foi identificado em quatro egressos do curso da EACH, que estão realizando mestrado e doutorado. Dentre eles, um assume a função de docente 
em cursos de nível superior, dois são bolsistas da Coordenação de Aperfeiçoamento de Pessoal de Nível Superior (CAPES) e um assume a função de monitoria, dentro da USP.

É importante destacar a diversidade de áreas e cursos que contemplam o rol de outras formações dos egressos do curso superior em Turismo e Lazer, apresentadas no Tabela 7.

Tabela 7 - Relação de cursos que compõem o processo de formação acadêmica dos egressos da EACH

\begin{tabular}{|c|c|}
\hline MODALIDADE DE ENSINO & CURSOS \\
\hline Curso Técnico & $\begin{array}{l}\text { Hotelaria; Turismo; Química; Informática; } \\
\text { Agenciamento de viagens; guia de turismo; Nutrição e } \\
\text { Dietética }\end{array}$ \\
\hline $\begin{array}{l}\text { Graduação } \\
\text { (concluída ou em andamento) }\end{array}$ & $\begin{array}{l}\text { Psicologia; Pedagogia; Ciências da Atividade Física; } \\
\text { Administração; Direito; Marketing; Engenharia de } \\
\text { Produção; Gestão de Políticas Públicas; Cinema; } \\
\text { Educação Física; Medicina Veterinária; História; } \\
\text { Arquitetura e Urbanismo e Geografia. }\end{array}$ \\
\hline $\begin{array}{l}\text { Pós-Graduação lato sensu } \\
\text { (concluída ou em andamento) }\end{array}$ & $\begin{array}{l}\text { Negócios Internacionais; Recreação e Lazer; Gestão } \\
\text { empresarial; Pesquisa de Mercado; Negócios do } \\
\text { Entretenimento; Gestão de Processos e Serviços; } \\
\text { Controladoria de Finanças e Produção Audiovisual. }\end{array}$ \\
\hline $\begin{array}{l}\text { Pós-Graduação stricto sensu } \\
\text { (concluída ou em andamento) }\end{array}$ & $\begin{array}{l}\text { Mestrado em Estudos Culturais; Mestrado em Educação } \\
\text { Profissional; Mestrado em Marketing Digital; Mestrado } \\
\text { em Mudança Social e Participação Política; Doutorado } \\
\text { em Educação; Mestrado acadêmico em Turismo; } \\
\text { Mestrado em Ciências da Atividade Física. }\end{array}$ \\
\hline
\end{tabular}

Fonte: Organizado pelos autores com base nas respostas dos egressos.

Analisando os perfis de formação de forma individual, percebemos que parte dos exalunos deu continuidade à carreira de bacharel em Lazer e Turismo, buscando outras qualificações, e outra parte (mais de 50\%) está investindo em outros segmentos. Essa diversidade de possibilidades de formação e atuação vai ao encontro do que Bauman (2001) aborda sobre a flexibilidade do mercado de trabalho. De acordo com o autor, a crença no trabalho a "longo prazo" cedeu lugar à concepção de trabalho a "curto prazo". Na modernidade sólida, um jovem aprendiz que tivesse seu primeiro emprego numa fábrica terminaria sua vida profissional no mesmo lugar. No cenário flexível da contemporaneidade, porém, “um jovem americano com nível médio de educação espera mudar de emprego 11 (onze) vezes durante sua vida de trabalho" (p. 169). 
Nesse sentido, cabe registrar o tempo que os ex-alunos levaram para ingressar no mercado de trabalho após a conclusão do curso. Menos de $48 \%$ dos egressos da EACH não estão trabalhando na área em que se formaram. No entanto, mais de $74 \%$ dos que estão trabalhando foram contratados imediatamente após o término da graduação, como mostra o Gráfico 3.

Gráfico 3 - Tempo que os egressos da EACH levaram para ingressar no mercado de trabalho de lazer e turismo

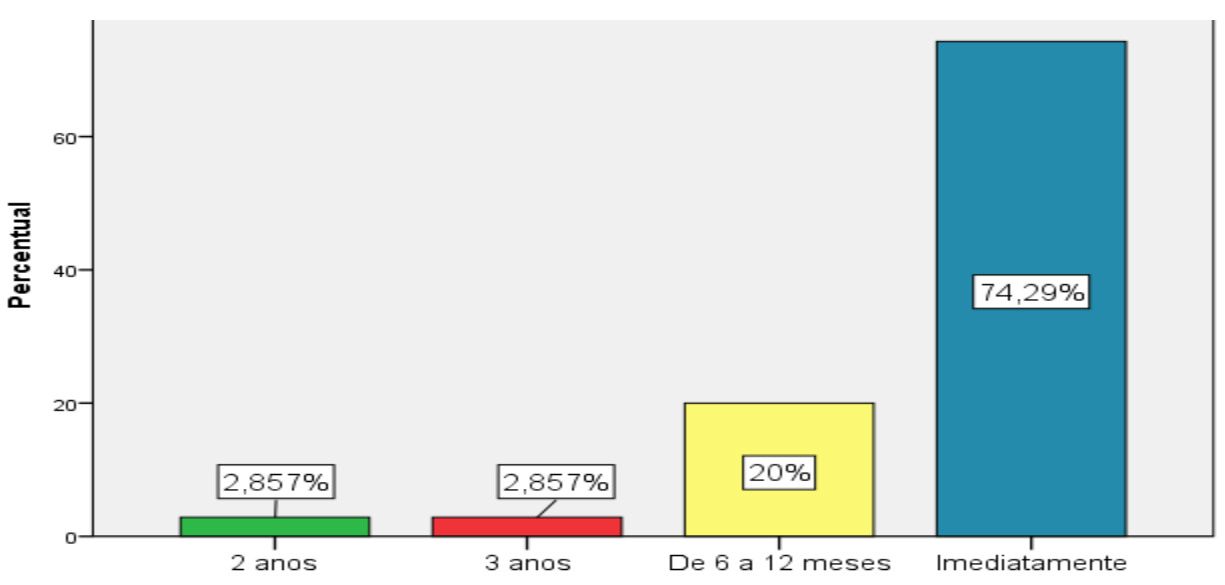

Fonte: Organizado pelos autores, com base nas respostas dos egressos.

Esse número pode mostrar que existe espaço para quem queira trabalhar nesta área, mas, é necessário estar qualificado para atender às necessidades desse segmento. Ao serem questionados, por exemplo, sobre o que facilitou seu ingresso imediato no mercado de trabalho, algumas questões se evidenciaram, como ter fluência em diferentes idiomas; ter realizado intercâmbio no exterior; ter construído uma rede de contatos (Networking); ter adquirido experiência profissional durante o curso e no período de estágio, além da influência do nome da USP como instituição formadora.

Por outro lado, quase $26 \%$ dos egressos tiveram alguma dificuldade para se inserirem no mercado de trabalho, o que foi atribuído a aspectos como não falar outro idioma; falta de compatibilidade com os requisitos da vaga e salário incompatível com o cargo. De acordo com Perrenoud (2002), Gondim (2008) e Perez Gomez (1992), estamos diante de um campo de atuação em constantes mudanças, que exige, portanto, profissionais flexíveis, ágeis e hábeis o suficiente para suprirem essa demanda.

No que diz respeito à atuação profissional, às dimensões relacionadas aos setores da 
sociedade e aos vínculos empregatícios, foi possível constatar, como mostra a Tabela 8 , que o setor privado é o que mais abriga os egressos do curso superior em Lazer e Turismo.

Tabela 8 - Setores em que os egressos da EACH estão atuando

\begin{tabular}{c|c|c|c}
\hline \multicolumn{2}{c}{} & \multicolumn{2}{c}{ RESPOSTAS } \\
\cline { 3 - 4 } \multicolumn{2}{c|}{} & Frequência & Percentual \\
\hline \multirow{2}{*}{$\begin{array}{c}\text { Setor em que atua } \\
(\text { EACH) }\end{array}$} & Setor privado & 31 & $81,6 \%$ \\
\cline { 2 - 4 } & Setor público & 3 & $7,9 \%$ \\
\cline { 2 - 4 } & Terceiro setor & 4 & $10,5 \%$ \\
\hline
\end{tabular}

Fonte: Organizado pelos autores, com base nas respostas dos egressos.

Optamos por fazer um cruzamento de dados entre o local de atuação e o segmento em que atuam, como forma de entender o que os egressos estão denominando de "lazer e turismo". Essa relação pode ser vista na Tabela 9. 
Tabela 9 - Relação entre o campo e local de atuação dos egressos da EACH

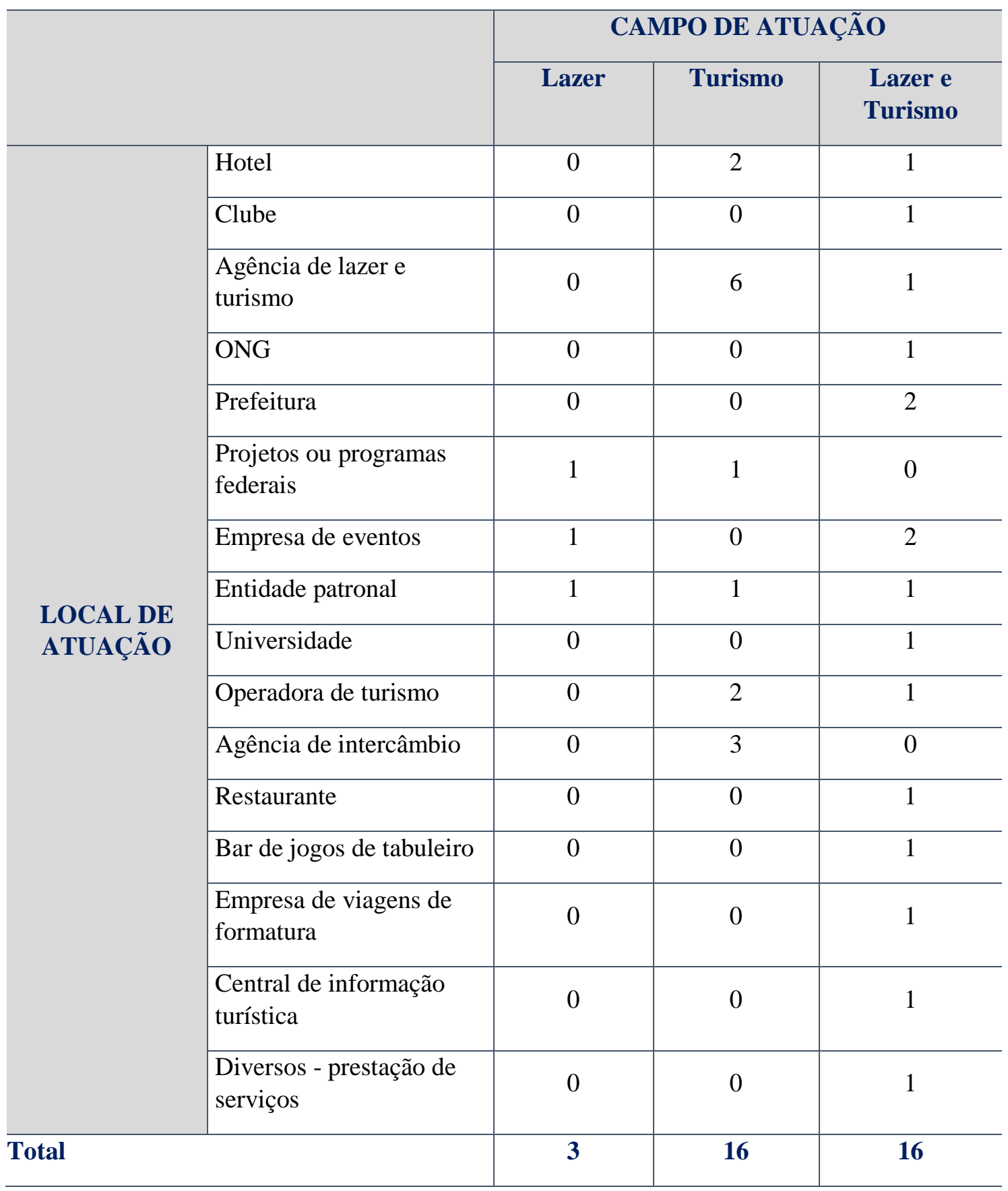

Fonte: Organizado pelos autores, com base nas respostas dos egressos.

Um ponto que chamou a atenção diz respeito ao fato de que a maioria que está trabalhando na área possui vínculo trabalhista, mediante carteira assinada, como mostra a Tabela 10. 
Tabela 10 - Relação de vínculos trabalhistas dos egressos que atuam na área

\begin{tabular}{l|l|c|c}
\hline \multirow{2}{*}{} & \multicolumn{2}{c}{ RESPOSTAS } \\
\cline { 2 - 4 } \multicolumn{2}{c|}{} & Frequência & Percentual \\
\hline \multirow{4}{*}{ Vínculo trabalhista } & Freelancer & 7 & $18,9 \%$ \\
\cline { 2 - 4 } & Autônomo & 3 & $8,1 \%$ \\
\cline { 2 - 4 } & Assalariado & $\mathbf{2 0}$ & $\mathbf{5 4 , 1 \%}$ \\
\cline { 2 - 4 } & Concursado & 3 & $8,1 \%$ \\
\cline { 2 - 4 } & Terceirizado & 1 & $2,7 \%$ \\
\cline { 2 - 4 } & Proprietário & 2 & $5,4 \%$ \\
\cline { 2 - 4 } & Bolsista & 1 & $2,7 \%$ \\
\hline
\end{tabular}

Fonte: Organizado pelos autores, com base nas respostas dos egressos.

Outros dois pontos a serem destacados e que também dão indícios de como está estruturado o mercado de trabalho em questão, diz respeito às jornadas de trabalho e à renda salarial daqueles que estão exercendo a profissão. De acordo com os dados coletados, a maioria trabalha mais que 40 horas semanais e recebe de 3 a 4 salários mínimos, como podemos visualizar nos Gráficos 4 e 5.

Gráfico 4 - Jornada de trabalho dos egressos da EACH que estão exercendo a profissão

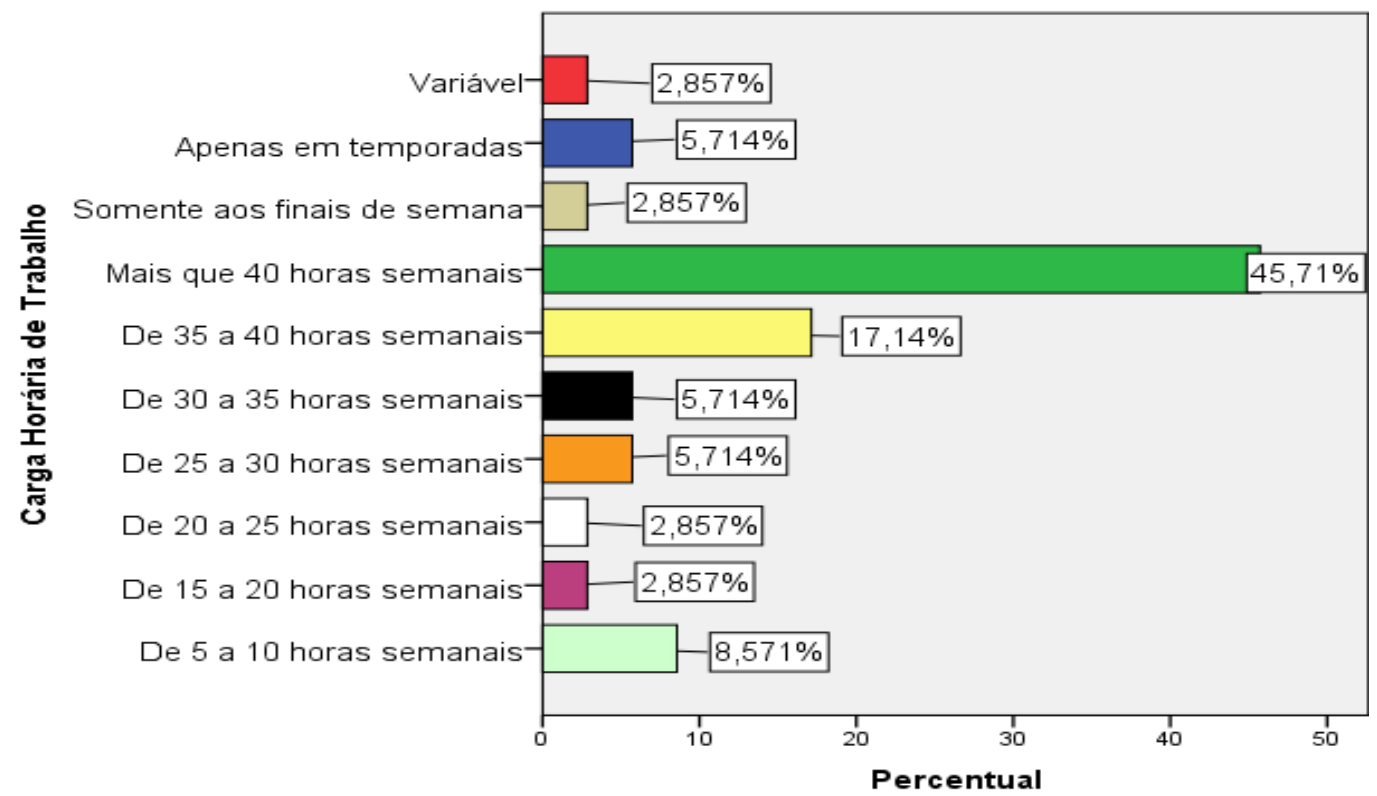

Fonte: Organizado pelos autores, com base nas respostas dos egressos. 
Gráfico 5 - Renda salarial mensal dos egressos que estão exercendo a profissão

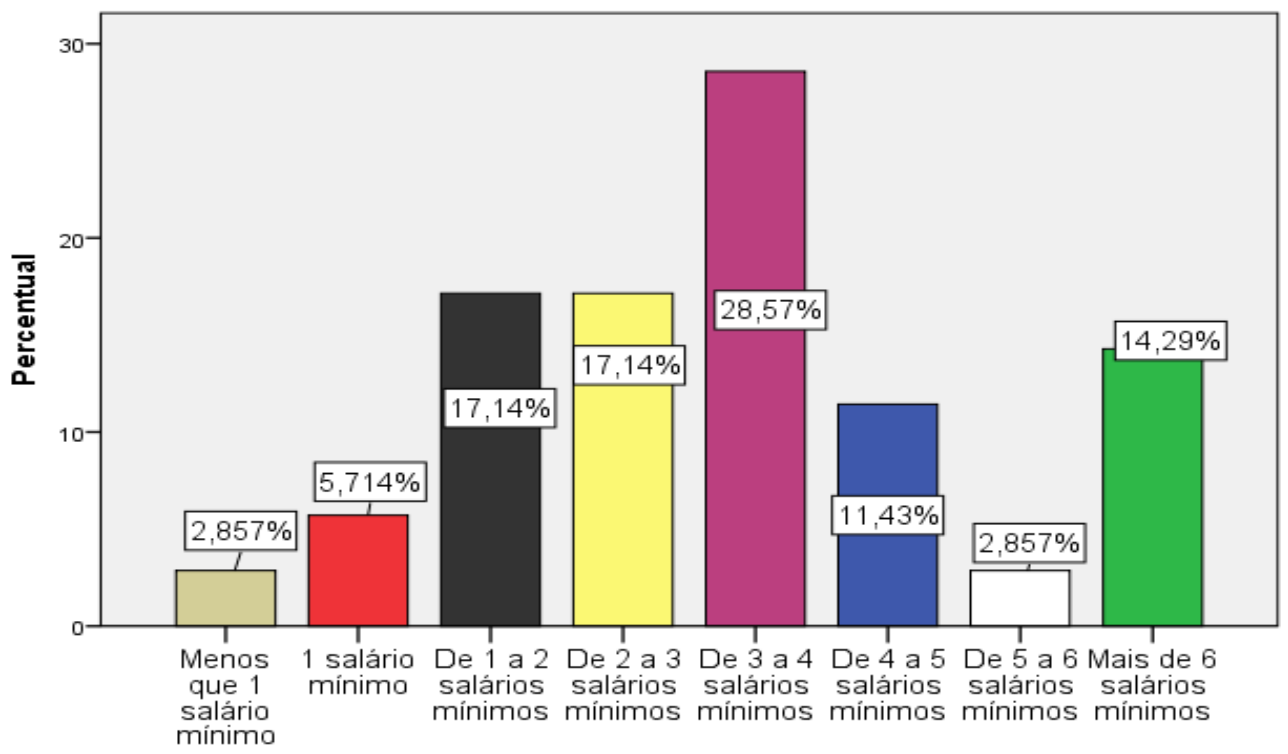

Fonte: Organizado pelos autores, com base nas respostas dos egressos.

Os dados apresentados não corroboram as preocupações de alguns autores da área do lazer, como Stoppa (2001), Isayama (2015), Gomes e Melo (2003) e Marcelino (2010), que apontam que a atuação no lazer, na maioria das vezes, configura-se por trabalhos realizados aos finais de semana e em temporadas e com um vínculo empregatício informal. Além disso, a renda salarial, muitas vezes, é questionada, mas se encontra acima da média da população brasileira.

Outra questão que propusemos analisar diz respeito às funções que os graduados em lazer e turismo assumem no mercado de trabalho. De acordo com os dados coletados, foi possível identificar que 38,2\% dos egressos do curso da EACH exercem funções de elaborar, coordenar e executar atividades no âmbito do lazer e do turismo e que 14,7\% coordenam tais atividades, como se pode verificar na Tabela 11. 
Tabela 11 - Funções que os egressos do curso superior desenvolvem

\begin{tabular}{|c|c|c|c|}
\hline & \multicolumn{2}{|c|}{ RESPOSTAS } \\
\hline & & Frequência ${ }^{(n)}$ & Percentual $(\%)^{11}$ \\
\hline \multirow{9}{*}{$\begin{array}{c}\text { Funções que Desenvolvem } \\
\text { (Egressos EACH) }\end{array}$} & Organiza Eventos & 6 & $17,6 \%$ \\
\hline & $\begin{array}{c}\text { Realiza a gestão da } \\
\text { empresa }\end{array}$ & 3 & $8,8 \%$ \\
\hline & Elabora atividades de lazer & 5 & $14,7 \%$ \\
\hline & $\begin{array}{l}\text { Elabora atividades de } \\
\text { turismo }\end{array}$ & 7 & $20,6 \%$ \\
\hline & Executa atividades de lazer & 5 & $14,7 \%$ \\
\hline & $\begin{array}{l}\text { Executa atividades de } \\
\text { turismo }\end{array}$ & 8 & 23,5 \\
\hline & $\begin{array}{c}\text { Coordena atividades de } \\
\text { lazer }\end{array}$ & 2 & 5,9 \\
\hline & $\begin{array}{c}\text { Coordena atividades de } \\
\text { turismo }\end{array}$ & 3 & 8,8 \\
\hline & Outros & 18 & 52,2 \\
\hline
\end{tabular}

Fonte: Organizado pelos autores, com base nas respostas dos egressos.

As funções de gerir uma empresa, desenvolver produtos ligados ao campo do lazer, assim como prestar consultoria nesse segmento também foram constatadas. Mediante análise dos documentos do curso, percebemos um aprofundamento da temática nos componentes curriculares da graduação da $\mathrm{EACH}$, com diferentes disciplinas direcionadas para gestão, consultoria e empreendedorismo, como, por exemplo: "Gestão e promoção de eventos I e II"; "Planejamento Estratégico do Lazer e do Turismo" e "Consultorias e empreendedorismo em Lazer e Turismo". Acreditamos que esse aprofundamento pode criar maiores possibilidades de atuação profissional no campo em questão.

${ }^{11}$ Observe que a soma das porcentagens ultrapassa $100 \%$. Isso ocorre devido à possibilidade do respondente assinalar mais de uma alternativa. 


\section{Considerações finais}

O presente artigo objetivou analisar a inserção no mercado de trabalho de egressos de um dos cursos que ofertam graduação em lazer no Brasil, buscando traçar um panorama desse campo de atuação, além de conhecer os setores aos quais os ex-alunos estão vinculados e as funções que desenvolvem.

Mediante análise dos dados, foi possível detectar que a maioria dos egressos do curso de Lazer e Turismo da EACH escolheu a respectiva área de formação por considerarem boas as possibilidades de inserção no mercado de trabalho. No entanto, a alta empregabilidade anunciada pelo curso e esperada pelos discentes não se concretizou, haja vista o percentual significante $(52,1 \%)$ de egressos que não estão exercendo a profissão. As justificativas dos mesmos para estarem fora do mercado para o qual se prepararam variam entre a não oportunidade de emprego; a decisão de investirem em outra formação e o fato de considerarem que o campo está desvalorizado, em termos econômicos. Nesse sentido, cabe a reflexão sobre a necessidade de cursos de formação específicos em lazer, uma vez que, devido ao aspecto interdisciplinar do campo, diferentes profissionais podem nele atuar.

Os dados coletados apontaram que a maioria dos egressos do referido curso que está exercendo a profissão inseriu-se no mercado de trabalho imediatamente após a conclusão do curso e atua no setor privado, assumindo funções diversas, como elaborar, executar e coordenar vivências de lazer e turismo. Além disso, os egressos pesquisados e atuantes no campo trabalham mais que 40 horas semanais e possuem uma renda salarial que varia de 3 a 4 salários mínimos, podendo ser avaliada como acima da média da população brasileira.

Este estudo surge como possibilidade de ampliar o debate, auxiliando na compreensão da conjuntura do campo do lazer. Consideramos que pesquisas com egressos representam uma forma de retratar a dinâmica do mercado de trabalho, além de favorecerem a avaliação dos processos formativos ofertados. Por conseguinte, espera-se que as brechas porventura encontradas no presente estudo despertem outras possibilidades de investigação, promovendo o aprofundamento das temáticas voltadas para a formação e a atuação profissional em lazer.

\section{Referências}

Aaker, D. A., Kumar, V., \& Day, G. S. (2007). Pesquisa de Marketing. São Paulo: Atlas. 
Lima e Santos, C. A. N., \& Isayama. H. F. (set./dez. 2020). Formação e atuação profissional: egressos do curso de

Abílio, L. C. (2018). Uberização do trabalho: subsunção real da viração. Retirado de: http://passapalavra.info/2017/02/110685.

Antunes, R. (2006). Adeus ao trabalho? ensaio sobre as metamorfoses e a centralidade do mundo do trabalho. São Paulo: Cortez; Campinas: Editora da UNICAMP.

Arruda, L. S. G. (2018). Perfil e Trajetória de Recreadores: Uma Análise da Atuação Profissional no Mercado de Trabalho. Dissertação. Universidade Federal de Minas Gerais, Mestrado em Estudos do Lazer.

Bardin, L. (2011). Análise de conteúdo. São Paulo: Edições 70, 2011.

Barros, A. J. S., \& Lehfeld, N. A. S. (2000). Fundamentos de Metodologia de Científica: um guia para iniciação científica. São Paulo: Makron Books.

Baumam, Z. (2001). Modernidade Líquida. Rio de Janeiro: Jorge Zahar.

Bell, C. V., Crebert, G., Patrick, M., \& Bates, C. J. (2003). Educating Australian Leisure Graduates: Contexts for Developing Generic Skills, Annals of Leisure Research, 6(1), 1-20.

Brasil. (1988). Constituição da República Federativa do Brasil de 1988. (1988, 05 de outubro) Brasília: Saraiva.

Escola de Artes, Ciências e Humanidades da Universidade de São Paulo. (2016). Bacharelado em Lazer e Turismo. Retirado de: http://each.uspnet.usp.br/site/graduacaocursos.php?item=lzt.

Escola de Artes, Ciências e Humanidades da Universidade de São Paulo. (2016). Projeto Político Pedagógico do Curso de Lazer e Turismo da Escola de Artes, Ciências e Humanidade da Universidade de São Paulo.

Gomes, C. L. (2006). Competências Profissionais para a Formação em Recreação. In: Congresso Nacional De Recreación, 9. Coldeportes/FUNLIBRE. Bogotá, D.C, Colombia.

Gomes, C. L., \& Melo, V. A. (2003). Lazer no Brasil: trajetória de estudos, possibilidades de pesquisa. Revista Movimento, Porto Alegre, 9(1), 23-44.

Gomes, C. L. (2008). Lazer, Trabalho e Educação: relações históricas, questões contemporâneas. Belo Horizonte: Ed. UFMG.

Gondim, S. M. G. (2008). Perfil Profissional e Mercado de Trabalho: relação com formação acadêmica pela perspectiva de estudantes. Estudos de Psicologia, Natal, 7(2), 299-309, , jul-dez.

Haworth, L. (2006). Leisure, work and profession. Leisure studies, 3(3), 319-334.

Henderson, K. A. (2011) A continuum of leisure studies and professional specialties: what if no connections exist?, World Leisure Journal, 53(2), 76-90.

doi:10.1080/04419057.2011.580547 
Instituto Brasileiro de Geografia e Estatística. (2018). Cidades. Retirado de: http://cidades.ibge.gov.br/v3/cidades/home-cidades.

Isayama, H. F. (2015). Formação Profissional no Âmbito do Lazer: Desafios e Perspectivas. In: ISAYAMA, Hélder Ferreira (org.). Lazer em estudo: currículo e formação profissional. (E-book). Campinas: Papirus.

Lyons, K. D., \& Brown, P. (2003). Enhancing the employability of leisure studies graduates through work integrated learning. Annals of Leisure Research, 6(1), 54-67.

Marcellino, N. C. (2010). A relação teoria e prática na formação profissional em lazer. In: Isayama, Hélder Ferreira (org.). Lazer em estudo: currículo e formação profissional. Campinas: Papirus.

Melo, V. A., \& Alves Júnior, E. (2012). Introdução ao lazer. São Paulo: Manole.

Msengi, I., Faland, J., Pedescleaux, J., McGloster, M. \&, Yang, H. (2007). Program effectiveness and curriculum competencies of the leisure youth and human services division at a Midwesten University: Does the curriculum meet the needs of the leisure profession? Schole: A jornal of Leisure Studies and Recreation Education, 22(1), 85-99.

Perez Gomez, A. (1992). O Pensamento Prático do Professor: a formação do professor como profissional reflexivo. In Nóvoa, A. (org.). Os Professores e a sua Formação. Lisboa: Dom Quixote.

Perrenoud, P. (2002). A Prática Reflexiva no Ofício de Professor: profissionalização e razão pedagógica. Porto Alegre: Artmed.

Pochmann, M. (2010). A Atualidade da Categoria Trabalho na Sociedade de Reestruturação Produtiva. In: Psicologia Crítica do Trabalho na Sociedade Contemporânea. Conselho Federal de Psicologia. - Brasília: CFP.

Pochmann, M. (2015). O emprego na globalização: A nova divisão internacional do trabalho e os caminhos que o Brasil escolheu. Coleção Mundo do Trabalho - Boitempo Editorial.

Sahuquillo, M. R. (2018). Trabalhadores Ultraflexíveis. Retirado de: https://brasil.elpais.com/brasil/2015/05/01/internacional/1430504838_853098.html.

Santos, C. A. N. L. E., \& Isayama, H. F. (2014). O Currículo de Cursos Técnicos de Lazer no Brasil: Um Estudo de Caso da Formação Profissional. Revista Brasileira de Estudos Pedagógicos RBEP-INEP, 95, 276-303.

São Paulo. (2016). Parecer de Reconhecimento de Curso de Lazer e turismo. Universidade de São Paulo.

Schön, D. A. (2000). Educando o profissional reflexivo: um novo design para o ensino e a aprendizagem. Porto Alegre: Artmed. 
Sennett, R. (2009). A Corrosão do caráter: as consequências pessoais do trabalho do novo capitalismo. Rio de Janeiro: Record.

Schreck, C. M., Weilbach, J. T., \& Reitsma, G. (2019). Preparing recreation professionals: graduate attributes expected of entry-level recreation professionals in a South African context. World Leisure Journal, 1-15. doi:10.1080/16078055.2019.1615542

Silva, G. S., \& Isayama, H. F. (2017). Lazer e Acampamentos de Férias: Análise de Currículos de Formação Profissional. IMPULSO, 27, 33-54.

Sistema de Informações sobre o Mercado de Trabalho. (2018). Sistema de Informações sobre o Mercado de Trabalho no Setor Turismo. Retirado de: http://www.ipea.gov.br/extrator/arquivos/180228_tutorial_extrator_dados_turismo.pdf.

Stoppa, E. A. (2001). Lazer e mercado de trabalho. Licere. Belo Horizonte, 3(1),176-181.

Tardif, M. (2008). Princípios para guiar a aplicação dos programas de formação inicial para o ensino. In Encontro Nacional de Didática e Prática de Ensino (ENDIPE), 14. Anais... Porto Alegre: Ed. da PUC, p.17-41.

Werneck, C. L. G. (2001) Lazer e mercado: panorama atual e implicações na sociedade brasileira. In Werneck, C. L. G.; Stoppa, E. A. \& Isayama, H. F. Lazer e mercado. Campinas: Papirus. 